Original article

\title{
The effects of emotional lability, mind wandering and sleep quality on ADHD symptom severity in adults with ADHD
}

\author{
Bartosz Helfer $^{\mathrm{a}, *}$, Ruth E. Cooper ${ }^{\mathrm{a}, \mathrm{b}}$, Natali Bozhilova ${ }^{\mathrm{a}}$, Stefanos Maltezos ${ }^{\mathrm{a}, \mathrm{c}}$, \\ Jonna Kuntsi ${ }^{a}$, Philip Asherson ${ }^{a}$ \\ a Institute of Psychiatry, Psychology and Neuroscience, King's College London, UK \\ ${ }^{\mathrm{b}}$ Newham Centre for Mental Health, Unit for Social and Community Psychiatry, Blizard Institute, Queen Mary University of London, UK \\ c Adult ADHD Service, South London and Maudsley NHS Foundation Trust, UK
}

\section{A R T I C L E IN F O}

\section{Article history:}

Received 27 June 2018

Received in revised form 20 September 2018

Accepted 22 September 2018

Available online 29 October 2018

\section{Keywords:}

Attention-deficit/hyperactivity disorder

Adults

Mind wandering

Sleep quality

Emotional lability

\begin{abstract}
A B S T R A C T
Mind wandering, emotional lability and sleep quality are currently mostly independently investigated but are all interlinked and play a major role is adult attention-deficit/ hyperactivity disorder (ADHD). Emotional lability is a core feature of the disorder, excessive mind wandering has recently been linked to symptoms and impairments of ADHD and poor sleep quality is experienced by a clear majority of adults with ADHD. All three phenomena lead to functional impairment in ADHD, however their relationship to each other and to ADHD symptom severity is not well understood. Here we used serial multiple mediation models to examine the influence of mind wandering, sleep quality and emotional lability on ADHD symptom severity. 81 adults diagnosed with ADHD participated in this study. We found that mind wandering and emotional lability predicted ADHD symptom severity and that mind wandering, emotional lability and sleep quality were all linked and significantly contributed to the symptomatology of adult ADHD. Mind wandering was found to lead to emotional lability which in turn lead to ADHD symptom severity; and poor sleep quality was found to exacerbate mind wandering leading to ADHD symptoms. Future research should employ objective on-task measures of mind wandering, sleepiness and emotional lability to investigate the neural basis of these impairing deficits in ADHD.
\end{abstract}

(c) 2018 Elsevier Masson SAS. All rights reserved.

\section{Introduction}

\subsection{ADHD and emotional lability}

Attention-deficit/hyperactivity disorder (ADHD) is a pervasive neurodevelopmental disorder affecting $5-6 \%$ of children and 3$4 \%$ of adults [1,2]. In both children and adults ADHD is characterized by age-inappropriate and impairing levels of inattention, hyperactivity and impulsivity [3]. According to DSM-5 measures of emotional lability can be used in a supportive capacity to help establish the diagnosis of adult ADHD. This can include a number of symptoms such as high irritability, changing moods or low frustration threshold [4]. Emotional lability is also a prominent feature of borderline personality disorder and bipolar disorder [4], which are both common comorbidities of ADHD $[5,6]$. However, it has been argued that emotional lability

\footnotetext{
* Corresponding author.

E-mail address: bartosz.helfer@kcl.ac.uk (B. Helfer).
}

in adults with ADHD is not related to comorbid conditions, but is a core feature of the disorder [7]. This is supported by multiple lines of evidence: emotional lability is present in adults with ADHD without psychiatric comorbidities [8], it responds well to ADHD medication $[9,10]$ and is related to functional impairment beyond other symptoms of ADHD [11]. Moreover, genetic studies indicate shared genes explain the strong link of ADHD to emotional lability [12].

\subsection{ADHD and mind wandering}

Mind wandering is an omnipresent life experience, when our mind drifts away from a primary task and focuses on internal, taskunrelated thoughts and images. It has been defined as a shift of attention from the external environment towards inner, selfgenerated, task-unrelated and stimulus-independent thoughts, decoupled from immediate sensory perceptions $[13,14]$. It is estimated that up to $50 \%$ of our daily lives are spent in a mind wandering state $[15,16]$. Mind wandering can be spontaneous and unintentional, which is often detrimental to the task at hand and 
have little strategic value to the individual; or deliberate, when it may be related to strategic thinking about future plans [17]. Excessive spontaneous mind wandering has recently been proposed as a candidate mechanism leading to the symptoms and impairments of ADHD, as it correlates strongly with ADHD symptom domains and impairment scores [18-21], and mind wandering is closely associated with default mode network (DMN) activity [22-24] and dysregulation of the DMN is a prominent feature of ADHD [21]. Mind wandering and ADHD symptoms have been examined predominantly in populations of college students not diagnosed with ADHD $[25,18,20,26]$. These studies found that spontaneous mind wandering is positively associated with ADHD symptom severity [18], both when measured in the laboratory as well as in daily life [20]. Participants with a childhood diagnosis of ADHD reported more task-unrelated thoughts compared with other participants [25].

\subsection{ADHD and sleep quality}

Poor sleep quality and the resulting sleep deprivation have profound consequences on daily human functioning, negatively affecting cognition and emotion [27]. Lack of good quality sleep disrupts normal wakefulness resulting in inattention [28-30]. Excessive daytime sleepiness due to disrupted sleep is extremely common in the general population [31] as well as in children and adults with ADHD [32,33]. Furthermore, adults with ADHD report higher excessive daytime sleepiness relative to healthy controls [34]. A variety of sleep problems are associated with ADHD [35]. It is estimated that up to 78\% of adults with ADHD experience sleep problems [36,37] and report lower sleep quality than neurotypical controls [38-41]. Sleep problems are thought to add to lower quality of life in ADHD, and are also associated with poorer academic performance, obesity, as well as more negative relations with carers [42]. Sleep disorders may also generate ADHD-like symptoms which can make differential diagnosis challenging $[43,44]$. There is a positive correlation between mind wandering and poor sleep quality or difficulty falling asleep in the general population [45] and a single night of sleep deprivation can increase mind wandering. Poor sleep quality as well as a range of sleep problems has also been linked to difficulties in emotion regulation and negative mood [46-48].

\subsection{Default mode network activity}

The DMN consists of interconnected cortical regions, including ventromedial prefrontal cortex and posterior cingulate cortex, which are activated (positively correlated) during rest and deactivated (anti-correlated) in response to attentional demands [49]. Individuals with ADHD have disturbed DMN connectivity leading to hyperactivation of DMN during daily activities [50], which is hypothesised to lead to excessive mind wandering [21]. Connectivity in the DMN can also be altered by any sleep-related reduction of consciousness [51], such as sleep deprivation [52-54]. DMN is also one of the crucial brain networks responsible for selfreferential processing and emotion regulation [55-57] and failure to downregulate the DMN activity has been linked to depressive ruminations [58]. Finally, mind wandering is well-known to cause transient dysphoric mood [16].

\subsection{Impairment}

ADHD, mind wandering and poor sleep quality are all associated with increased rates of car accidents while driving [59-62] and together with emotional lability they contribute to poor academic performance $[63,11,64,14]$. Emotional lability leads to multiple functional impairments 0 [11].

\subsection{Aim and hypotheses}

In summary, it is striking that ADHD, excessive mind wandering, poor sleep quality and emotional lability bear such a close resemblance in their negative effects on everyday functioning and share a close association with disrupted activity within the DMN. Despite this, these concepts have never been investigated together. Therefore, in the present study we aim to investigate the effect of mind wandering, emotional lability and sleep quality on the severity of symptoms of ADHD in a sample of adults diagnosed with ADHD. Based on the literature reviewed above, we hypothesize that all three variables will significantly exacerbate the symptomatology of ADHD. We further hypothesize that the independent variables will be causally linked: 1) mind wandering will lead to emotional lability [16] which would lead to ADHD symptom severity $[9,11,8,7]$; and 2) poor sleep quality would lead to emotional lability [46-48] and mind wandering [65,66], which would lead to ADHD symptom severity [7,21].

\section{Methods}

\subsection{Sample}

The data presented here is part of a larger study (Oils and Cognitive Effects in Adult ADHD Neurodevelopment, ClinicalTrials. gov Identifier: NCT01750307). In total 81 English-speaking adults with ADHD volunteered to participate in the study (60 male, 51 female, mean age 32.4 years, SD 10 years, mean IQ 110, SD 13). Diagnosis was made according to the DMS-5 criteria [4]. Participants were recruited via South London and Maudsley Adult ADHD Outpatient Services (see Table 1 for detailed characteristics).

\subsection{Clinical measures}

ADHD symptoms were measured using the Conners' Adult ADHD Rating Scales (CAARS) [68], a self-report 18-item scale assessing the level of inattention and hyperactivity/ impulsivity consistent with the DSM-5 criteria for adult ADHD [4]. Emotional Lability was measured with the Affective Lability Scale (ALS) [69] a self-report 18-item scale sensitive to swift changes in emotion and mood.

Mind wandering was measured with the Mind Excessively Wandering Scale (MEWS) [19], a reliable self-report 12-item questionnaire developed on the basis of ADHD patients' descriptions of their thought processes: capturing thoughts constantly on the go, thoughts flitting from one topic to another and multiple overlapping thoughts at the same time. The MEWS is thought to be especially sensitive in detecting unintentional and uncontrollable mind wandering that is closely related to ADHD [19,17,26]. MEWS has been validated against experience sampling data in daily life (Moukhtarian et al., unpublished data), and was significantly correlated with measures of spontaneous but not deliberate mind

Table 1

Background, clinical and cognitive variables of the study sample.

\begin{tabular}{lll}
\hline \multirow{2}{*}{ Gender } & Participants with ADHD \\
& N=81 & 44 males (54\%) \\
& Mean & SD \\
\hline Age (years) & 33.5 & 10.3 \\
IQ & 109.4 & 13.7 \\
ADHD Symptom Severity (CAARS) & 65.7 & 15.7 \\
Emotional Lability (ALS) & 17.9 & 7.1 \\
Mind Wandering (MEWS) & 23.6 & 7.9 \\
Sleep Quality (PSQI) & 14.1 & 6.8 \\
\hline
\end{tabular}

Note. MEWS: Mind Excessively Wandering Scale; PSQI: Pittsburgh Sleep Quality Index; ALS: Affective Lability Scale; CAARS: Conners' Adult ADHD Rating Scales. 
wandering in a community sample (Mowlem et al., unpublished data).

Sleep quality was measured using the Pittsburgh Sleep Quality Index (PSQI) [70], a 19-item questionnaire with high validity and reliability in retrospective self-assessment of disturbed sleep quality over the last month, including the ensuing daytime dysfunction [71]. PSQI broadly assess both quantitative (sleep latency, number of awakenings) and qualitative (restlessness, functioning) aspects of sleep and its utility is established in both clinical and non-clinical populations [72]. PSQI covers several indications for sleep disorders using the following seven component scores: 1) subjective sleep quality; 2) sleep latency; 3) sleep duration; 4) habitual sleep efficiency; 5) sleep disturbances; 6) use of sleeping medication; 7) daytime dysfunction [70]. People with ADHD who additionally suffer from sleep problems show difficulties across all these seven components [73].

\subsection{Statistical analyses}

We conducted serial multiple mediation modelling using ordinary least squares path analysis in PROCESS [74]. For the estimation of the indirect effects of the independent variables on the outcome variable via the intermediary variables we used $95 \%$ bias-corrected bootstrap confidence intervals $(\mathrm{CI})$ based on 10,000 bootstrapping samples. A confidence interval was considered statistically significant when it was entirely above or below zero. The two-tailed alpha was set at 0.05 for all analyses.

\section{Results}

A multiple regression was run to predict ADHD symptom severity from mind wandering, sleep quality and emotional lability. There was linearity as assessed by partial regression plots and a plot of studentized residuals against the predicted values. There was independence of residuals, as assessed by a DurbinWatson statistic of 1.970. There was homoscedasticity, as assessed by visual inspection of a plot of studentized residuals versus unstandardized predicted values. There was no evidence of multicollinearity, as assessed by tolerance values greater than 0.1 . The assumption of normality was met, as assessed by a Q-Q Plot.

The multiple regression model statistically significantly predicted ADHD symptom severity, $F(3,74)=86.969, p<.001$. $R^{2}$ for the overall model was $77.9 \%$ with an adjusted $R^{2}$ of $77.0 \%$, a large effect size according to Cohen (1988). Mind wandering and emotional lability added statistically significantly to the prediction, $\mathrm{p}<.05$. Regression coefficients and standard errors are presented in Table 2.

All study variables were significantly positively correlated, see Table 3.

As mediators in model A (emotional lability and sleep quality) were significantly correlated, $r(78)=0.377, \mathrm{p}<0.001$ ) as well as in model B (mind wandering and emotional lability), $r(78)=0.575, \mathrm{p}$ $<0.001$ we run a serial multiple mediation models (see Fig. 1).

Table 2

Summary of Multiple Regression Analysis.

\begin{tabular}{lllll}
\hline Variable & $B$ & $S E_{B}$ & $\beta$ & Sig. \\
\hline Intercept & 25.464 & 2.913 & & 0.000 \\
Mind wandering & 0.419 & 0.136 & 0.212 & 0.003 \\
Sleep Quality & 0.067 & 0.14 & 0.029 & 0.634 \\
Emotional Lability & 1.614 & 0.152 & 0.73 & 0.000 \\
\hline
\end{tabular}

Note. $B=$ unstandardized regression coefficient; $S E_{B}=$ Standard error of the coefficient; $\beta=$ Standardized coefficient.
Table 3

Summary of Correlations.

\begin{tabular}{lllll}
\hline Variable & $\begin{array}{l}\text { Mind } \\
\text { Wandering } \\
\text { (MEWS) }\end{array}$ & $\begin{array}{l}\text { Sleep } \\
\text { Quality } \\
\text { (PSQI) }\end{array}$ & $\begin{array}{l}\text { Emotional } \\
\text { Lability } \\
\text { (ALS) }\end{array}$ & $\begin{array}{l}\text { ADHD } \\
\text { Symptom } \\
\text { Severity } \\
\text { (CAARS) }\end{array}$ \\
\hline Mind Wandering (MEWS) & & 0.389 & 0.575 & 0.639 \\
Sleep Quality (PSQI) & & & 0.377 & 0.387 \\
Emotional Lability (ALS) & & & & 0.867 \\
\hline
\end{tabular}

Note. MEWS: Mind Excessively Wandering Scale; PSQI: Pittsburgh Sleep Quality Index; ALS: Affective Lability Scale; CAARS: Conners' Adult ADHD Rating Scales. All correlations are statistically significant at the level 0.001, two-tailed.

\subsection{Model $A$}

The model (see Table 4 ) was statistically significant, $R=0.65$, $\mathrm{R}^{2}=0.42, \mathrm{~F}(1,76)=54.84, \mathrm{p}<0.001$. We found a significant direct effect of mind wandering on ADHD symptom severity $\left(c^{\prime}=0.42, p=\right.$ 0.003 ). There was a strong association between mind wandering and emotional lability $(\mathrm{a} 2=0.46, \mathrm{p}<0.001)$ as well as between mind wandering and sleep quality ( $a 1=0.33, \mathrm{p}=0.000)$. We found a significant effect of emotional lability on ADHD symptom severity ( $b 2=1.61, p<0.001$ ), but no effect of sleep quality on ADHD symptom severity ( $b 1=0.07, p=0.634$ ). The effect of mind wandering on ADHD symptom severity was mediated by emotional lability (Ind3 $=0.74,95 \%$ CI $0.49-1.04$ ), but not sleep quality (Ind $1=0.02,95 \% \mathrm{CI}:-0.07$ to 0.13 ). However, the interaction between the mediators also yielded a statistically significant mediatory effect where sleep quality affected emotional lability (Ind $2=0.10,95 \%$ CI 0.01 to 0.25 ).

\subsection{Model B}

The model (see Table 5) was statistically significant, $R=0.39$, $R^{2}=0.15, F(1,76)=13.38, p=0.001$. There was no statistically significant direct effect of sleep quality on ADHD symptom severity $\left(c^{\prime}=0.07, p=0.634\right)$. There was a strong effect of sleep quality on mind wandering ( $\mathrm{a} 1=0.45, \mathrm{p}<0.001$ ), but no significant effect of sleep quality on emotional lability ( $a 2=0.19, p=0.079$ ). Again, we found a significant effect of mind wandering on ADHD symptom severity (b1 $=0.42, p=0.003$ ), as well as emotional lability on ADHD symptom severity ( $\mathrm{b} 2=1.61, \mathrm{p}<0.001$ ). As there was no significant direct effect, the influence of sleep quality on ADHD symptom severity was completely mediated by mind wandering ( Ind $1=0.19,95 \% \mathrm{CI} 0.06$ to 0.41 ) and emotional lability (Ind $3=0.30,95 \% \mathrm{CI} 0.01$ to 0.62 ). The interaction between the mediators was also statistically significant (Ind $2=0.34,95 \%$ CI 0.16 to 0.60 ).

\section{Discussion}

We found that mind wandering and emotional lability predicted ADHD symptom severity and that mind wandering, emotional lability and sleep quality are all linked and significantly contribute to the symptomatology of adult ADHD. The mediation models supported both our prior hypotheses. Mind wandering was found to lead to emotional lability which in turn leads to ADHD symptom severity; and poor sleep quality was found to exacerbate mind wandering leading to ADHD symptoms.

Our findings fit well into the previous findings. We confirmed that mind wandering and emotional lability are significantly linked with core deficits in adult ADHD [9,11,8,18,7,19,20,21] and that poor sleep quality may lead to emotional dysregulation [46-48] as well as exacerbate mind wandering $[65,66]$. We have also confirmed an influential result that mind wandering could lead to emotional lability and negative emotions [16]. 

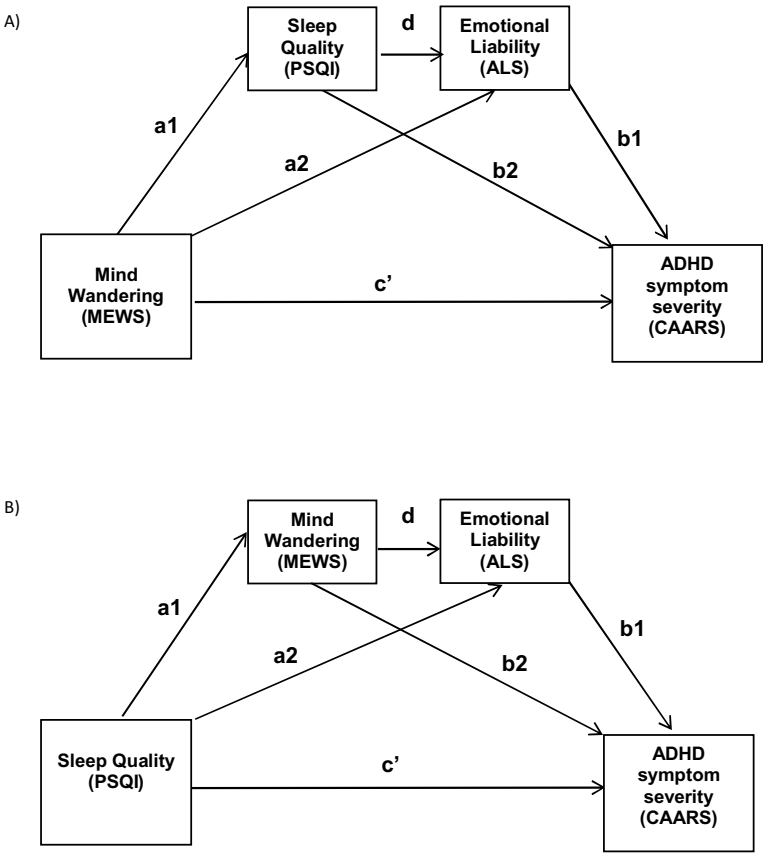

Note. MEWS: Mind Excessively Wandering Scale; PSQI: Pittsburgh Sleep Quality Index; ALS: Affective Lability Scale; CAARS: Conners' Adult ADHD Rating Scales.

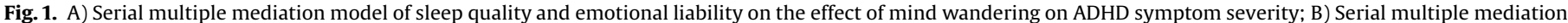
model of mind wandering and emotional liability on the effect of sleep quality on ADHD symptom severity.

Note. MEWS: Mind Excessively Wandering Scale; PSQI: Pittsburgh Sleep Quality Index; ALS: Affective Lability Scale; CAARS: Conners' Adult ADHD Rating Scales.

Table 4

Results from the serial multiple mediation model of the intermediary effect of sleep quality and emotional lability on the relationship between mind wandering and ADHD symptom severity.

\begin{tabular}{lllll}
\hline & \multicolumn{4}{l}{ Mediators: (1) Sleep Quality (PSQI) and (2) Emotional Lability (ALS) } \\
\cline { 2 - 5 } & \multicolumn{4}{l}{ Mind Wandering (MEWS) $\rightarrow$ ADHD Symptom Severity (CAARS) } \\
\cline { 2 - 5 } & Coefficient/ Effect & SE & $\mathrm{t}$ & $\mathrm{p}$ \\
\hline a1 & 0.33 & 0.09 & 3.68 & 0.000 \\
a2 & 0.46 & 0.09 & 5.12 & 0.000 \\
b1 & 0.07 & 0.14 & 0.48 & 0.634 \\
b2 & 1.61 & 0.15 & 10.65 & 0.000 \\
d & 0.19 & 0.10 & 1.78 & 0.079 \\
c' & 0.42 & 0.14 & 3.08 & 0.003 \\
c & 1.28 & 0.17 & 7.41 & 0.000 \\
Ind1 & 0.02 & 0.05 & $95 \%$ CI: -0.07 to 0.13 \\
Ind2 & 0.10 & 0.06 & $95 \%$ CI: 0.01 to 0.25 \\
Ind3 & 0.74 & 0.14 & $95 \%$ CI: 0.49 to 1.04 \\
model & \multicolumn{5}{l}{0.000} \\
\hline
\end{tabular}

Note. MEWS: Mind Excessively Wandering Scale; PSQI: Pittsburgh Sleep Quality Index; ALS: Affective Lability Scale; CAARS: Conners' Adult ADHD Rating Scales; CI: 95\% Bootstrapping Confidence Intervals.

c': direct effect of the independent variable (Emotional Liability in A or Sleep Quality in B) on the outcome variable (ADHD Symptom Severity);

a: effect of the independent variable on the intermediary variable (Emotional Liability in A or Sleep Quality in. B);

b: effect of the intermediary variable on the outcome variable; c: total effect, which is the sum of the direct and indirect effects;

$\mathrm{d}$ : serial effect of mediator 1 (Sleep Quality) on mediator 2 (Emotional Lability); Ind: indirect effect of the independent variable on the outcome variable via the intermediary variables;

Ind1: MEWS $\rightarrow$ PSQI $\rightarrow$ CAARS

Ind2: MEWS $\rightarrow$ PSQI $\rightarrow$ ALS $\rightarrow$ CAARS.

Ind3: MEWS $\rightarrow$ ALS $\rightarrow$ CAARS.
Table 5

Results from the serial multiple mediation model of the intermediary effect of mind wandering and emotional lability on the relationship between sleep quality and ADHD symptom severity.

\begin{tabular}{|c|c|c|c|c|}
\hline & \multicolumn{4}{|c|}{$\begin{array}{l}\text { Mediators: (1) Mind Wandering (MEWS) and (2) Emotional Lability } \\
\text { (ALS) }\end{array}$} \\
\hline & \multicolumn{4}{|c|}{ Sleep Quality (PSQI) $\rightarrow>$ ADHD Symptom Severity (CAARS) } \\
\hline & Coefficient/ Effect & SE & $\mathrm{t}$ & $\mathrm{p}$ \\
\hline a1 & 0.45 & 0.12 & 3.68 & 0.000 \\
\hline a2 & 0.19 & 0.10 & 1.78 & 0.079 \\
\hline b1 & 0.42 & 0.14 & 3.08 & 0.003 \\
\hline b2 & 1.61 & 0.15 & 10.65 & 0.000 \\
\hline $\mathrm{d}$ & 0.46 & 0.09 & 5.12 & 0.000 \\
\hline$c^{\prime}$ & 0.07 & 0.14 & 0.48 & 0.634 \\
\hline c & 0.89 & 0.24 & 3.66 & 0.001 \\
\hline Ind1 & 0.19 & 0.09 & \multicolumn{2}{|c|}{ 95\% CI: 0.06 to 0.41} \\
\hline Ind2 & 0.34 & 0.11 & \multicolumn{2}{|c|}{$95 \%$ CI: 0.16 to 0.60} \\
\hline Ind3 & 0.30 & 0.16 & \multicolumn{2}{|c|}{$95 \% \mathrm{CI}: 0.01$ to 0.62} \\
\hline model & \multicolumn{3}{|c|}{$R=0.39, R^{2}=0.15, F(1,76)=13.38$} & 0.001 \\
\hline
\end{tabular}

Note. MEWS: Mind Excessively Wandering Scale; PSQI: Pittsburgh Sleep Quality Index; ALS: Affective Lability Scale; CAARS: Conners' Adult ADHD Rating Scales; CI: 95\% Bootstrapping Confidence Intervals.

c': direct effect of the independent variable (Emotional Liability in A or Sleep Quality in B) on the outcome variable (ADHD Symptom Severity);

a: effect of the independent variable on the intermediary variable (Emotional Liability in A or Sleep Quality in. B);

b: effect of the intermediary variable on the outcome variable:

c: total effect, which is the sum of the direct and indirect effects;

$\mathrm{d}$ : serial effect of mediator 1 (Sleep Quality) on mediator 2 (Emotional Lability); Ind: indirect effect of the independent variable on the outcome variable via the intermediary variables;

Ind1: PSQI $\rightarrow$ MEWS $\rightarrow$ CAARS

Ind 2: PSQI $\rightarrow$ MEWS $\rightarrow$ ALS $\rightarrow$ CAARS.

Ind3: PSQI $\rightarrow$ ALS $\rightarrow$ CAARS. 


\subsection{Limitations}

It should be noted, that even though we would like to hypothesise that the links between the variables are causal and despite the fact that the mediation model itself encourages a causal interpretation of the links between the variables [74], the crosssectional nature of our data limits the causal inferences that can be drawn from these analyses [75]. Therefore, we based our model on a specific a priori hypothesis developed based on a theoretical model that arises from empirical observations linking the constructs investigated here [76,77]. To investigate the causal nature of these hypotheses, further studies using a longitudinal design or experimental manipulations will be required.

\subsection{Mind wandering and emotional lability}

In this study, we have investigated a specific hypothesis that mind wandering leads to emotional lability. This is based on one of the most influential studies in the field, investigating mind wandering in a neurotypical group, where it has been found that mind wandering was the cause, and not a consequence, of negative feelings [16]. However, another prominent study found that negative mood can lead to more mind wandering [78] and today it is generally acknowledged that emotional processes play a major, if not the central, role in generation of mental content during mind wandering [14]. It seems that mind wandering and emotional lability are so closely linked that a two-way process might be a best explanation for the existing data. Mind wandering is a cause of emotional dysregulation when the negative content of the thought, or the intrusive nature of mind wandering itself, leads to higher levels of stress, including emotional distress, which in turn enhances the level of task-unrelated, negatively-valanced thoughts. Such a mechanism seems to be especially plausible in adults with ADHD, as the mind wandering experiences in ADHD are more intrusive and excessive [21], and there is emotional overactivity to stressful events [8]. Mind wandering and emotional lability in adults with ADHD are both an integral part of the disorder [7], and this may be underpinned by abnormal activity in the DMN [79,21]. This reasoning can be additionally supported by the fact that mindfulness-based treatments for adults with ADHD seem to be promising and the preliminary data suggest high efficacy [80]. Mindfulness and meditation practices are known to normalize activity and connectivity in the DMN and lead to decreased mind wandering and improved emotion regulation [81]. Further work is however needed to test the hypotheses arising from our study.

\subsection{Sleep, emotional lability and mind wandering}

We found a similar bi-directional relationship between sleep quality and mind wandering, which is in line with previous findings in neurotypical subjects [65]. It seems that not only poor sleep quality and the resulting sleep deprivation leads to higher incidence of mind wandering [66], but also a restless wandering mind makes it harder to fall asleep. It should be noted that one of the items on the MEWS scale, which was used to measure mind wandering in our study, reads: "Because my mind is 'on the go' at bedtime, I have difficulty falling off to sleep" [19]. Mind wandering and sleepiness are similar in terms of the EEG signal and are both linked to the DMN activity [82]. Moreover, poor sleep quality results in negative affect [65], which is also in line with our findings regarding sleep quality and emotional lability. As discussed above, because mind wandering and emotional lability are so closely linked via negative affect, even when poor sleep quality exacerbates one of the variables, inevitably both of them will be increased $[83,45]$, especially in adults suffering from ADHD.

\subsection{Future directions}

In summary, this study aimed to link the currently mostly independently investigated concepts of emotional lability, mind wandering, sleep quality and adult ADHD. Future studies should employ experimental on-task measures of mind wandering (experience sampling), sleepiness (event-related potentials, quantitative electroencephalography and polysomnography) and frustration tasks to objectively measure emotional lability; and link them to the activity of the DMN using neuroimaging and experimental designs involving ADHD medication and mindfulness training. Investigating these concepts in diverse samples, across developmental stages and diagnostic categories, holds a big promise in fully uncovering the causal mechanism behind these impairing deficits.

\section{Declaration of interest}

Professor Asherson has received funds for consultancy on behalf of King's College London to Shire, Eli-Lilly, and Novartis, regarding the diagnosis and treatment of ADHD; educational/ research awards from Shire, Eli-Lilly, Novartis, Vifor Pharma, GW Pharma, and QbTech; speaker at sponsored events for Shire, EliLilly, and Novartis. All funds are used for studies of ADHD. Ruth Cooper has received funding from Vifor Pharma. The other authors report no conflicts of interest.

\section{Acknowledgements}

We would like to thank The National Adult ADHD Clinic at the South London and Maudsley Hospital (SLaM) and all study participants. The OCEAN study was funded by Vifor Pharma (PADWUDB), awarded to Philip Asherson with King's College London as sponsor. Bartosz Helfer is supported by the European Union's Horizon 2020 research and innovation programme under the Marie Sklodowska-Curie grant agreement no. 643051. Professor Asherson is supported by NIHR Biomedical Research Centre for Mental Health, NIHR/MRC (14/23/17), Action Medical Research (GN 2315) and European Union (643051, 602805 and 667303). This study reflects the authors' views and none of the funders holds any responsibility for the information provided.

\section{References}

[1] Fayyad J., De Graaf R, Kessler R, Alonso J, Angermeyer M, Demyttenaere K, De Girolamo G, Haro JM, Karam EG, Lara C, Lepine JP, Ormel J, Posada-Villa J, Zaslavsky AM, Jin R. Cross-national prevalence and correlates of adult attention-deficit hyperactivity disorder. Br J Psychiatry 2007:190:402-9.

[2] Polanczyk G, de Lima MS, Horta BL, Biederman J, Rohde LA. The worldwide prevalence of ADHD: a systematic review and metaregression analysis. Am J Psychiatry 2007;164(6):942-8.

[3] Faraone SV, Asherson P, Banaschewski T, Biederman J, Buitelaar JK, RamosQuiroga JA, Rohde LA, Sonuga-Barke EJ, Tannock R, Franke B. Attentiondeficit/ hyperactivity disorder. Nat Rev Dis Primers 2015;1:15020.

[4] APA. Diagnostic and statistical manual of mental disorders (DSM-5®). American Psychiatric Pub; 2013.

[5] Kessler RC, Adler L, Barkley R, Biederman J, Conners CK, Demler O, Faraone SV, Greenhill LL, Howes MJ, Secnik K. The prevalence and correlates of adult ADHD in the United States: results from the National Comorbidity Survey Replication. Am J Psychiatry 2006;163(4):716-23.

[6] Moukhtarian TR, Mintah RS, Moran P, Asherson P. Emotion dysregulation in attention-deficit/hyperactivity disorder and borderline personality disorder. Borderline Personality Disorder and Emotion Dysregulation 2018;5(1):9.

[7] Asherson P, Buitelaar J, Faraone SV, Rohde LA. Adult attention-deficit hyperactivity disorder: key conceptual issues. Lancet Psychiatry 2016;3 (6):568-78.

[8] Skirrow C, Asherson P. Emotional lability, comorbidity and impairment in adults with attention-deficit hyperactivity disorder. J Affect Disord 2013;147 $(1-3): 80-6$.

[9] Skirrow C, McLoughlin G, Kuntsi J, Asherson P. Behavioral, neurocognitive and treatment overlap between attention-deficit/hyperactivity disorder and mood instability. Expert Rev Neurother 2009;9(4):489-503. 
[10] Moukhtarian T, Cooper R, Vassos E, Moran P, Asherson P. Effects of stimulants and atomoxetine on emotional lability in adults: a systematic review and meta-analysis. Eur Psychiatry 2017;44:198-207.

[11] Barkley RA, Fischer M. The unique contribution of emotional impulsiveness to impairment in major life activities in hyperactive children as adults. J Am Acad Child Adolesc Psychiatry 2010;49(5):503-13.

[12] Merwood A, Chen W, Rijsdijk F, Skirrow C, Larsson H, Thapar A, Kuntsi J, Asherson P. Genetic associations between the symptoms of attention-deficit/ hyperactivity disorder and emotional lability in child and adolescent twins. J Am Acad Child Adolesc Psychiatry 2014;53(2)209-20 e204.

[13] Stawarczyk D, Majerus S, Maquet P, D'Argembeau A. Neural correlates of ongoing conscious experience: both task-unrelatedness and stimulusindependence are related to default network activity. PLoS One 2011;6(2) e16997.

[14] Smallwood J, Schooler JW. The science of mind wandering: empirically navigating the stream of consciousness. Annu Rev Psychol 2015;66:487-518.

[15] Kane MJ, Brown LH, McVay JC, Silvia PJ, Myin-Germeys I, Kwapil TR. For whom the mind wanders, and when: an experience-sampling study of working memory and executive control in daily life. Psychol Sci 2007;18(7):614-21.

[16] Killingsworth MA, Gilbert DT. A wandering mind is an unhappy mind. Science 2010;330(6006):932.

[17] Seli P, Risko EF, Smilek D. On the necessity of distinguishing between unintentional and intentional mind wandering. Psychol Sci 2016;27(5):685-91.

[18] Seli P, Smallwood J, Cheyne JA, Smilek D. On the relation of mind wandering and ADHD symptomatology. Psychon Bull Rev 2015;22(3):629-36.

[19] Mowlem FD, Skirrow C, Reid P, Maltezos S, Nijjar SK, Merwood A, Barker E, Cooper R, Kuntsi J, Asherson P. Validation of the mind excessively wandering scale and the relationship of mind wandering to impairment in adult ADHD. J Atten Disord 20161087054716651927.

[20] Franklin MS, Mrazek MD, Anderson CL, Johnston C, Smallwood J, Kingstone A, et al. Tracking distraction. J Atten Disord 2017;21(6):475-86.

[21] Bozhilova N, Michelini G, Kuntsi J, Asherson P. Mind wandering perspective on ADHD. Neurosci Biobehav Rev 2018.

[22] McKiernan KA, D'Angelo BR, Kaufman JN, Binder JR. Interrupting the "stream of consciousness": an fMRI investigation. Neuroimage 2006;29(4):1185-91.

[23] Mason MF, Norton MI, Van Horn JD, Wegner DM, Grafton ST, Macrae CN. Wandering minds: the default network and stimulus-independent thought. Science 2007;315(5810):393-5.

[24] Fox KC, Spreng RN, Ellamil M, Andrews-Hanna JR, Christoff K. The wandering brain: meta-analysis of functional neuroimaging studies of mind-wandering and related spontaneous thought processes. Neuroimage 2015;111:611-21.

[25] Shaw GA, Giambra L. Task-unrelated thoughts of college-students diagnosed as hyperactive in childhood. Dev Neuropsychol 1993;9(1):17-30.

[26] Jonkman LM, Markus CR, Franklin MS, van Dalfsen JH. Mind wandering during attention performance: effects of ADHD-inattention symptomatology, negative mood, ruminative response style and working memory capacity. PLoS One 2017;12(7)e0181213.

[27] Krause AJ, Simon EB, Mander BA, Greer SM, Saletin JM, Goldstein-Piekarski AN, et al. The sleep-deprived human brain. Nat Rev Neurosci 2017;18(7):404-18.

[28] Pilcher JJ, Huffcutt AI. Effects of sleep deprivation on performance: a metaanalysis. Sleep 1996;19(4):318-26.

[29] Dinges DF, Pack F, Williams K, Gillen KA, Powell JW, Ott GE, Aptowicz C, Pack AI. Cumulative sleepiness, mood disturbance, and psychomotor vigilance performance decrements during a week of sleep restricted to 4-5 hours per night. Sleep 1997;20(4):267-77.

[30] Durmer JS, Dinges DF. Neurocognitive consequences of sleep deprivation. Semin Neurol 2005;25(1):117-29.

[31] Lund HG, Reider BD, Whiting AB, Prichard JR. Sleep patterns and predictors of disturbed sleep in a large population of college students. J Adolesc Health 2010;46(2):124-32.

[32] Cortese S, Faraone SV, Konofal E, Lecendreux M. Sleep in children with attentiondeficit/hyperactivity disorder: meta-analysis of subjective and objective studies. J Am Acad Child Adolesc Psychiatry 2009;48(9):894-908.

[33] Hvolby A. Associations of sleep disturbance with ADHD: implications for treatment. Attent Deficit Hyperactiv Disorders 2015;7(1):1-18.

[34] Bjorvatn B, Brevik EJ, Lundervold AJ, Halmoy A, Posserud MB, Instanes JT, et al. Adults with attention deficit hyperactivity disorder report high symptom levels of troubled sleep, restless legs, and cataplexy. Front Psychol 2017;8:1621.

[35] Konofal E, Lecendreux M, Cortese S. Sleep and ADHD. Sleep Med 2010;11 (7):652-8.

[36] Yoon SY, Jain U, Shapiro C. Sleep in attention-deficit/hyperactivity disorder in children and adults: past, present, and future. Sleep Med Rev 2012;16(4):371-88.

[37] Kooij JS, Bijlenga D. The circadian rhythm in adult attention-deficit/ hyperactivity disorder: current state of affairs. Expert Rev Neurother 2013;13(10):1107-16.

[38] Boonstra AM, Kooij JJ, Oosterlaan J, Sergeant JA, Buitelaar JK, Van Someren EJ. Hyperactive night and day? Actigraphy studies in adult ADHD: a baseline comparison and the effect of methylphenidate. Sleep 2007;30(4):433-42.

[39] Schredl M, Alm B, Sobanski E. Sleep quality in adult patients with attention deficit hyperactivity disorder (ADHD). Eur Arch Psychiatry Clin Neurosci 2007;257(3):164-8.

[40] Sobanski E, Schredl M, Kettler N, Alm B. Sleep in adults with attention deficit hyperactivity disorder (ADHD) before and during treatment with methylphenidate: a controlled polysomnographic study. Sleep 2008;31 (3):375-81.
[41] Surman CB, Adamson JJ, Petty C, Biederman J, Kenealy DC, Levine M, Mick E, Faraone SV. Association between attention-deficit/hyperactivity disorder and sleep impairment in adulthood: evidence from a large controlled study. J Clin Psychiatry 2009;70(11):1523-9.

[42] Um YH, Hong SC, Jeong JH. Sleep problems as predictors in attention-deficit hyperactivity disorder: causal mechanisms, consequences and treatment. Clin Psychopharmacol Neurosci 2017;15(1):9-18.

[43] Oosterloo M, Lammers GJ, Overeem S, de Noord I, Kooij JJ. Possible confusion between primary hypersomnia and adult attention-deficit/hyperactivity disorder. Psychiatry Res 2006;143(2-3):293-7.

[44] Bioulac S, Micoulaud-Franchi JA, Philip P. Excessive daytime sleepiness in patients with ADHD-diagnostic and management strategies. Curr Psychiatry Rep 2015;17(8):608.

[45] Ottaviani C, Couyoumdjian A. Pros and cons of a wandering mind: a prospective study. Front Psychol 2013;4:524.

[46] Gruber R, Cassoff J. The interplay between sleep and emotion regulation: conceptual framework empirical evidence and future directions. Curr Psychiatry Rep 2014;16(11):500.

[47] Gobin CM, Banks JB, Fins AI, Tartar JL. Poor sleep quality is associated with a negative cognitive bias and decreased sustained attention. J Sleep Res 2015;24 (5):535-42.

[48] Palmer CA, Alfano CA. Sleep and emotion regulation: an organizing, integrative review. Sleep Med Rev 2017;31:6-16.

[49] Buckner RL, Andrews-Hanna JR, Schacter DL. The brain's default network: anatomy, function, and relevance to disease. Ann N Y Acad Sci 2008;1124:1-38.

[50] Christakou A, Murphy CM, Chantiluke K, Cubillo AI, Smith AB, Giampietro V, Daly E, Ecker C, Robertson D, Murphy DG, Rubia K. Disorder-specific functional abnormalities during sustained attention in youth with attention deficit hyperactivity disorder (ADHD) and with autism. Mol Psychiatry 2013;18 (2):236-44

[51] Horovitz SG, Braun AR, Carr WS, Picchioni D, Balkin TJ, Fukunaga M, et al Decoupling of the brain's default mode network during deep sleep. Proc Nat Acad Sci U S A 2009;106(27):11376-81.

[52] Gujar N, Yoo SS, Hu P, Walker MP. The unrested resting brain: sleep deprivation alters activity within the default-mode network. J Cogn Neurosci 2010;22 (8):1637-48.

[53] De Havas JA, Parimal S, Soon CS, Chee MW. Sleep deprivation reduces default mode network connectivity and anti-correlation during rest and task performance. Neuroimage 2012;59(2):1745-51.

[54] Dai XJ, Liu CL, Zhou RL, Gong HH, Wu B, Gao L, et al. Long-term total sleep deprivation decreases the default spontaneous activity and connectivity pattern in healthy male subjects: a resting-state fMRI study. Neuropsychiatr Dis Treat 2015;11:761-72.

[55] Andrews-Hanna JR. The brain's default network and its adaptive role in internal mentation. The Neuroscientist 2012;18(3):251-70.

[56] Andrews-Hanna JR, Smallwood J, Spreng RN. The default network and selfgenerated thought: component processes, dynamic control, and clinical relevance. Ann NY Acad Sci 2014;1316(1):29-52.

[57] Pan J, Zhan L, Hu C, Yang J, Wang C, Gu L, Zhong S, Huang Y, Wu Q, Xie X, Chen Q. Zhou H, Huang M, Wu X. Emotion regulation and complex brain networks: association between expressive suppression and efficiency in the fronto-parietal network and default-mode network. Front Hum Neurosci 2018;12(70).

[58] Sheline YI, Barch DM, Price JL, Rundle MM, Vaishnavi SN, Snyder AZ, Mintun MA Wang S, Coalson RS, Raichle ME. The default mode network and selfreferential processes in depression. Proc Natl Acad Sci 2009;106(6):1942-7.

[59] Lyznicki JM, Doege TC, Davis RM, Williams MA, A. Am Med. Sleepiness, driving, and motor vehicle crashes. Jama-J Am Med Assoc 1998;279(23):1908-13.

[60] Connor J, Norton R, Ameratunga S, Robinson E, Civil I, Dunn R, Bailey J, Jackson R. Driver sleepiness and risk of serious injury to car occupants: population based case control study. Br Med J 2002;324(7346):1125-1128A.

[61] Cowley JA. Off task thinking types and performance decrements during simulated automobile driving. Proc Hum Factors Ergonom Soc Annu Meet 2013;57(1):1214-8.

[62] Yanko MR, Spalek TM. Driving with the wandering mind: the effect that mindwandering has on driving performance. Hum Factors 2014;56(2):260-9.

[63] Doi Y, Minowa M, Tango T. Impact and correlates of poor sleep quality in Japanese white-collar employees. Sleep 2003;26(4):467-71.

[64] Dewald JF, Meijer AM, Oort FJ, Kerkhof GA, Bogels SM. The influence of sleep quality, sleep duration and sleepiness on school performance in children and adolescents: a meta-analytic review. Sleep Med Rev 2010;14(3):179-89.

[65] Carciofo R, Du F, Song N, Zhang K. Mind wandering, sleep quality, affect and chronotype: an exploratory study. PLoS One 2014;9(3)e91285.

[66] Poh J-H, Chong PL, Chee MW. Sleepless night, restless mind: effects of sleep deprivation on mind wandering. J Exp Psychol Gen 2016;145(10):1312.

[68] Conners CK, Erhardt D, Sparrow EP. Conners' adult ADHD rating scales (CAARS). North Tonawanda, multi-health systems. 1999.

[69] Oliver MNI, Simons JS. The affective lability scales: development of a shortform measure. Personal Individ Diff 2004;37(6):1279-88.

[70] Buysse DJ, Reynolds [170_TD\$DIFF][171_TD\$DIFF]3rd CF, Monk TH, Berman SR, Kupfer DJ. The Pittsburgh sleep quality index: a new instrument for psychiatric practice and research. Psychiatry Res 1989;28(2):193-213.

[71] Carpenter JS, Andrykowski MA. Psychometric evaluation of the Pittsburgh sleep quality index. J Psychosom Res 1998;45(1):5-13.

[72] Mollayeva T, Thurairajah P, Burton K, Mollayeva S, Shapiro CM, Colantonio A The Pittsburgh sleep quality index as a screening tool for sleep dysfunction in 
clinical and non-clinical samples: a systematic review and meta-analysis. Sleep Med Rev 2016;25:52-73.

[73] Mulraney M, Sciberras E, Lecendreux M. ADHD and sleep. Oxford textbook of attention deficit hyperactivity disorder. . p. 280.

[74] Hayes A. Introduction to mediation, moderation, and conditional process analysis: a regression-based approach. New York: Guilford Press; 2013.

[75] Winer ES, Cervone D, Bryant J, McKinney C, Liu RT, Nadorff MR. Distinguishing mediational models and analyses in clinical psychology: atemporal associations Do not imply causation. J Clin Psychol 2016;72(9):947-55.

[76] Axelrod V, Rees G, Lavidor M, Bar M. Increasing propensity to mind-wander with transcranial direct current stimulation. Proc Natl Acad Sci U S A 2015;112 (11):3314-9.

[77] Gallo EF, Posner J. Moving towards causality in attention-deficit hyperactivity disorder: overview of neural and genetic mechanisms. Lancet Psychiatry 2016;3(6):555-67.
[78] Smallwood J, Fitzgerald A, Miles LK, Phillips LH. Shifting moods, wandering minds: negative moods lead the mind to wander. Emotion 2009;9(2):271.

[79] Shaw P, Stringaris A, Nigg J, Leibenluft E. Emotion dysregulation in attention deficit hyperactivity disorder. Am J Psychiatry 2014;171(3):276-93.

[80] Cairncross M, Miller CJ. The effectiveness of mindfulness-based therapies for ADHD: a meta-analytic review. J Atten Disord 20161087054715625301.

[81] Mitchell JT, Zylowska L, Kollins SH. Mindfulness meditation training for attentiondeficit/hyperactivity disorder in adulthood: current empirical support, treatment overview, and future directions. Cognit Behav Pract 2015;22(2):172-91.

[82] Braboszcz C, Delorme A. Lost in thoughts: neural markers of low alertness during mind wandering. Neuroimage 2011;54(4):3040-7.

[83] McVay JC, Kane MJ, Kwapil TR. Tracking the train of thought from the laboratory into everyday life: an experience-sampling study of mind wandering across controlled and ecological contexts. Psychonom Bull Rev 2009;16(5):857-63. 